\title{
0 modelo de gestão de pessoas por competências: um estudo de caso em um órgão público federal sobre os fatores que afetam a implantação deste modelo
}

Dyhele de Macêdo Silva Lima dyhelemacedo@gmail.com
Centro Universitário Projeção $\begin{array}{lr}\text { Centro } & \text { Universitário } \\ \text { (UNIPROJEÇÃO), Taguatinga, Distrito }\end{array}$ Federal, Brasil

José Airton Mendonça de Melo jose.melo@projecao.br Centro Universitário Projeção (UNIPROJEÇÃO), Taguatinga, Distrito Federal, Brasil

\begin{abstract}
RESUMO
O estudo busca identificar a percepção dos colaboradores de um órgão público federal sobre os principais fatores que afetam a implantação do modelo de gestão pessoas por competências, GPC, assim, como identificar a natureza desses fatores. Quanto ao nível da pesquisa, utilizou-se o método descritivo e como procedimentos de coleta de dados, a pesquisa bibliográfica e um estudo de caso, com 40 servidores do órgão, selecionados por amostragem não aleatória e por conveniência. Para encontrar a natureza dos fatores, segundo o padrão de variação das características, empregou-se uma análise fatorial exploratória do tipo $\mathrm{R}$, a fim de identificar grupos de fatores com o maior grau de independência possível. Quanto aos achados da pesquisa, destacam-se, quanto à percepção, que todas as pessoas entrevistadas tinham conhecimento do modelo de GPC; todos possuíam competências necessárias para o alcance da missão organizacional; e mais da metade concordou que, por ser um novo modelo de gestão de pessoas, há muitas dificuldades para definir o mapa de competências, entre eles, a resistência à mudança. Quanto à natureza, o método agrupou os 15 itens do questionário em cinco variáveis latentes, de acordo o padrão de variação das características dos itens.
\end{abstract}

PALAVRAS-CHAVE: Gestão de Pessoas. Gestão por Competências. Análise Fatorial. Variáveis Latentes. 


\section{INTRODUÇÃO}

Quando se fala em recrutamento de pessoas em uma organização, logo vêm em mente aqueles processos seletivos para preenchimentos de vagas existentes. No serviço público, a porta de entrada ocorre por meio de aprovação em concurso público. Então como atrair a pessoa certa para a vaga certa de forma que atinja os objetivos organizacionais? É nesse contexto que se revela a gestão de pessoas por competências, GPC, uma vez que utiliza uma metodologia de mapeamento das competências organizacionais, juntamente com o mapeamento das capacidades que compõem os perfis de cada cargo necessários para o alcance da missão organizacional. Selecionando as pessoas para o exercício de uma função conforme as suas qualificações e habilidades pertinentes.

Segundo Carbone et al. (2009), a GPC visa basicamente ao gerenciamento de lacunas de competências existentes na organização, procurando eliminá-las ou minimizá-las. O propósito é aproximar as competências existentes na organização daquelas necessárias para o alcance dos objetivos organizacionais.

A adoção desse modelo de gestão tem aumentado o interesse das organizações, tendo em vista nortear seus esforços para planejar, captar, desenvolver e avaliar as competências necessárias ao alcance de suas metas (FERREIRA, 2015).

O foco desse tipo de gestão são as pessoas e suas competências, entre as que já estão desenvolvidas e as que são um potencial a serem aprimoradas. O princípio base é o capital humano, o maior responsável por favorecer e entregar os resultados esperados no nível de excelência pretendido. E a crença em um modelo de gestão de pessoas que valoriza a competência de cada servidor, que de fato contribui para o alcance da missão institucional.

Assim, o objetivo geral deste estudo é identificar a percepção dos colaboradores de um órgão do Poder Judiciário no Distrito Federal sobre os principais fatores que afetam a implantação do modelo de GPC, assim como identificar a natureza desses fatores, contemplando os seguintes objetivos específicos de levantamento teórico que responda e fundamente uma resposta ao problema do estudo; de identificação e conceituação dos métodos de pesquisa utilizados; e de desenvolvimento de um diagnóstico sobre a situação do estudo de caso, a fim de detectar as principais dificuldades na implantação do modelo de GPC no órgão a ser estudado.

As hipóteses levantadas foram as seguintes: i) dificuldade associada à cultura organizacional; ii) contratação de uma consultoria especializada sobre o assunto e capacitar os funcionários no sistema informatizado escolhido; e iii) os gastos financeiros são altos e sem o apoio ou patrocínio da Alta Administração torna-se difícil executar esta gestão.

Quanto ao nível de pesquisa, foi adotado o método descritivo e como técnicas de coleta de dados, levantamento bibliográfico e uma pesquisa de campo, na modalidade estudo de caso.

Assim, além desta introdução, a pesquisa está estruturada em quatro seções. A primeira compreende a revisão teórica, que aborda os conceitos e teorias relacionadas à gestão por competência. A segunda trata da metodologia. A terceira é a análise dos resultados. E na última seção são apresentadas as conclusões e considerações finais do estudo, acompanhadas de algumas 
propostas de melhorias para a organização objeto do estudo de caso.

\section{REVISÃO TEÓRICA}

A presente seção aborda a revisão teórica sobre o conceito de competência, tipos, gestão, GPC em organizações públicas, aborda-se ainda as dificuldades de implantação. Tem o propósito de levantar a fundamentação teórica que responda ao objetivo do trabalho de identificar quais as principais dificuldades e natureza para a implantação do modelo de GPC no setor público.

\section{CONCEITO DE COMPETÊNCIA}

A definição de competência foi proposta pela primeira vez em 1973, por David McClelland, quando publicou um artigo titulado Testing for Competence Rather Than Intelligence (Testando por Competência em vez de Inteligência), na busca de uma abordagem que fosse efetiva no que se refere aos testes de inteligência nos processos de recrutamento e seleção de pessoas para as organizações (DUTRA, 2007). Na década de 80, Boyatzis (1982) apresentou o conceito de competência como suporte nos processos de avaliação e crescimento profissional. Preocupado com assuntos relacionados à entrega do indivíduo para o ambiente no qual se insere.

Mais adiante, Hamel e Prahalad incrementaram a definição de competências essenciais e vantagem competitiva com o enfoque estratégico e organizacional (CHIAVENATO, 2014). Ainda a respeito desse termo, Rabaglio(2001, p.03) define-o "como um conjunto de conhecimentos, habilidades, atitudes que permitem ao indivíduo desempenhar, com eficácia determinadas tarefas em qualquer situação".

Este conjunto de conhecimentos, habilidades e atitudes é conhecido pela sigla $\mathrm{CHA}$, que segundo mostra a Figura 1 , suas características são de fundamental importância para o desenvolvimento das competências individuais, pois o conhecimento representa o "Saber", é o que se aprende nas faculdades, nos livros, no trabalho; a habilidade é o "Saber fazer", ou seja, são todos os conhecimentos que se utilizam no cotidiano; já a atitude representa o "Querer fazer", é o que nos leva a exercer a habilidade de um determinado conhecimento (LEME, 2015).

Figura 1 - Pilares das competências

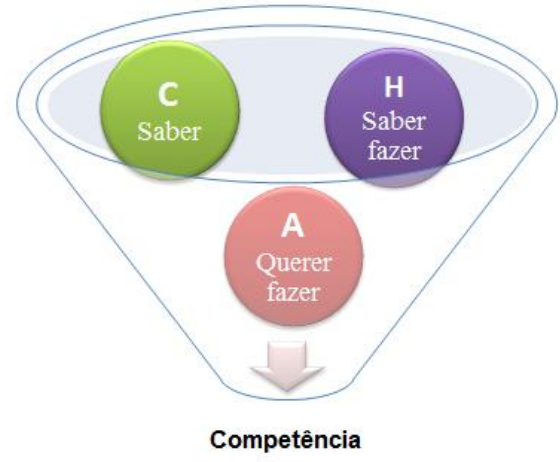

Fonte: Leme (2015), adaptado pelos autores 
Para Ferreira (2015), uma competência corresponde à junção do conhecimento, da habilidade e da atitude e contempla a agregação de valor e a entrega que o profissional faz para a empresa. Bloom et al. (1979) acrescentam que o conhecimento refere-se a informações que são adotadas e assimiladas pela pessoa em sua memória, causando influência sobre decisões ou comportamentos. É tudo o que a pessoa acumulou ao longo da vida, sua "bagagem", lembranças de conceitos, ideias ou situações. Já a habilidade é a execução do conhecimento, a capacidade do indivíduo de processar conhecimentos guardados na memória e utilizá-los em uma ação. A atitude, por sua vez, diz respeito a aspectos sociais e sentimentais; são sentimentos ou aptidões que dirigem a conduta em relação aos outros, a situações e a trabalhos.

Para compreender a aplicação do CHA, Gramigna (2007, apud FERREIRA, 2015) usa a metáfora da "árvore de competências", ao comparar o desenvolvimento da competência de uma pessoa com o crescimento de uma árvore. O tronco e os galhos representam o conhecimento, o conjunto de informações que a pessoa reúne e utiliza quando necessário. A raiz representa às atitudes, o conjunto de valores, princípios e crenças que são aprendidos durante a vida e que contribuem para o nível de envolvimento e comprometimento com o trabalho. Já a copa da árvore corresponde às habilidades, o exercer com talento, a capacidade e técnica, que proporcionam a obtenção de bons resultados no trabalho.

Dentro desse conceito de competência, Carbone et al. (2009, FERREIRA, 2015) acreditam na mesma definição que corresponde a um conjunto de conhecimentos, habilidades e atitudes necessários para o exercício de determinada atividade, e decorrente da aplicação destes, o desempenho expresso pela pessoa em termos de comportamentos e realizações.

Já Zarifian (2008) argumenta que a competência está centrada em ter iniciativa e responsabilidade do indivíduo diante de situações profissionais com as quais surgirem. Araujo (2016, p.49) explica essa mesma definição quando ressalta que "ser competente significa ir além das atividades prescritas, é ser capaz de compreender e dominar situações novas no trabalho, ser responsável e reconhecido por isso".

E por fim, Chiavenato (2014) afirma que é vantajoso trabalhar com competências porque permite direcionar o foco, concentrar esforços no que é necessário trabalhar para o alcance dos objetivos da empresa.

De acordo com Fleury e Fleury (2001 apud CARBONE et al. 2009), a competência decorre da combinação de insumos (conhecimentos, habilidades e atitudes) do indivíduo, conforme mostra a Figura 2. E sua competência é expressa quando gera um desempenho satisfatório no trabalho, seguido do CHA. Agregando valor econômico à organização e social para o indivíduo, contribuindo para o alcance dos objetivos organizacionais. 
Figura 2 - Competências como fonte de valor para o indivíduo e a organização

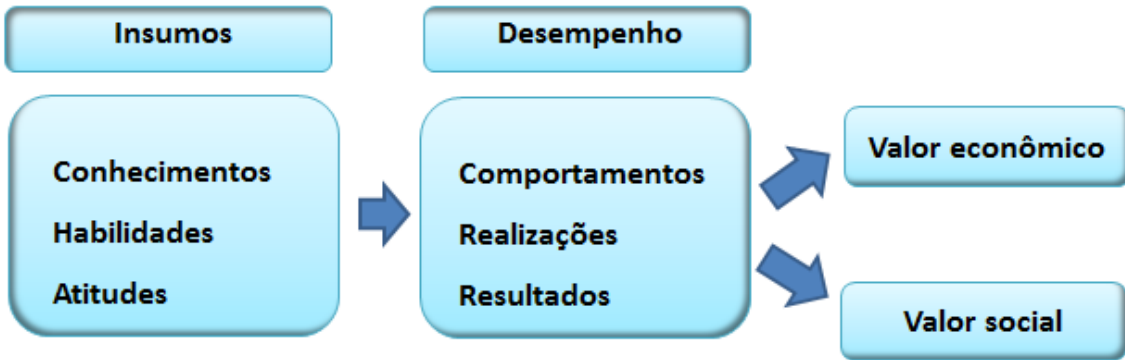

Fonte: Fleury e Fleury (2001 apud Carbone et al. 2009), adaptado pelos autores

Considerando ainda a Figura 2, Dutra (2002, apud ARAUJO, 2016) acredita que o simples fato de as pessoas possuírem um conjunto de conhecimentos, habilidades e atitudes, não garante que a organização será beneficiada no alcance dos seus objetivos. Pois, de acordo com aquele autor,

A passagem para a competência ocorre em função da capacidade da pessoa de entregar-se à empresa e apresentar, mediante suas realizações, os resultados que a organização espera e necessita. A pessoa é considerada competente quando, com suas capacidades, consegue com suas entregas, agregar valor à empresa, a ela própria e ao meio em que vive. A entrega, portanto, reflete um saber agir responsável e reconhecido, à medida que se torna possível identificar os resultados do trabalho realizado. (DUTRA, 2002, apud ARAUJO, 2016, p. 51).

\section{TIPOS DE COMPETÊNCIA}

As competências classificam-se em quatro categorias: organizacionais, individuais, técnicas e comportamentais. Segundo Fleury e Fleury (2000 apud ROCHA, 2016) as primeiras têm suas origens na abordagem da organização como uma dimensão de recursos, que contemplam elementos como infraestrutura, financeiro, imagem, marca, sistemas administrativos e recursos humanos.

Já Prahalad e Hamel (1990 apud ROCHA 2016) ressaltam que a competência organizacional seria a habilidade de combinar, agregar e integrar recursos em produtos e serviços. Ainda de acordo com esses autores, a habilidade e a capacidade não são pertencentes apenas ao indivíduo, mas também à empresa. Já para Zarifian (2001 apud ROCHA 2016), as competências sobre a organização compreendem saber planejar os fluxos de trabalho.

Voltando a Prahalad e Hamel (1990, apud ROCHA, 2016, p.65), é possível reconhecer as competências do indivíduo "como talentos específicos que só podem ser considerados dentro dos demais recursos da empresa". Nessa relação entre pessoa e empresa, a gestão de pessoas por competências estima uma troca que ocorre entre o que o indivíduo entrega à organização e o retorno da empresa ao indivíduo. Agregando assim, valor à empresa e ao indivíduo, acontecendo à aprendizagem organizacional (ROCHA, 2016).

As competências individuais, conforme Chiavenato (2014) são as capacidades que cada indivíduo deve conceber e desenvolver para atuar nas unidades da organização. Para Brandão (2012), a descrição deve demonstrar um desempenho 
ou comportamento esperado e indicar de forma clara o que o profissional deve ser capaz de fazer, além de ser descrito por verbo de ação.

Essas competências humanas ou individuais representam uma característica fundamental de um indivíduo, relacionada a um critério de eficácia no trabalho. Devem ser específicas em cada organização, área de conhecimento, processo ou cargo para que a pessoa apresente um determinado desempenho no trabalho (FERREIRA, 2015).

As competências técnicas são, segundo Leme (2011), todos os conhecimentos específicos ou métodos que o servidor precisa conhecer e dominar bem, para realizar as habilidades pertencentes à sua função, tais como aplicativos de informática, softwares de gestão, metodologias, idiomas, dentre outros. Compreende tudo o que o profissional necessita ter para desempenhar seu papel, e são evidenciadas pelo C e pelo H do CHA, o "Saber" e o "Saber Fazer".

A capacidade técnica, segundo Zarifian (2008), expressa que o indivíduo precisa conseguir conciliar os objetivos de desempenho organizacionais em seus atos técnicos quando assumir responsabilidade nas atividades profissionais. Sobre a diferença entre competências técnicas e comportamentais, as primeiras abrangeriam os conhecimentos e as habilidades ( $O$ saber e o saber fazer), enquanto as segundas representariam a atitude, (Querer fazer), apresentando o diferencial competitivo de cada profissional (LEME, 2007; RABAGLIO, 2008 apud FERREIRA, 2015).

\section{GESTÃO DE PESSOAS POR COMPETÊNCIAS}

A seleção de pessoas é o meio pelo qual a organização busca atender suas necessidades de profissionais, priorizando as pessoas mais qualificadas para ocupar um determinado cargo (FERREIRA, 2015).

Na ausência de candidatos com potencial para preenchimento de uma vaga, não tem como efetuar essa seleção. Por isso, o processo de recrutamento e seleção necessita de criatividade para atrair uma maior quantidade de pessoas com o perfil desejado. Para isso, faz-se necessário fazer a descrição detalhada do cargo, com pré-requisitos e competências fundamentais para determinado cargo ou posto de trabalho (FRANÇA, 2013).

Um dos passos para a implantação desse modelo de gestão é o mapeamento das competências. Para que a seleção possa ocorrer, é importante que a empresa já tenha mapeado suas competências organizacionais e aquelas que compõem os perfis de cada cargo ou função (FERREIRA, 2015). O mapeamento das competências institucionais é uma etapa de grande importância na execução do projeto, mas, se este for mal elaborado ou tiver baixa assertividade quanto aos desejos de atuação da instituição para com seus servidores, pode ser um fracasso (LEME, 2011).

A partir dos mapeamentos das competências necessárias para o alcance da missão organizacional, será possível verificar as lacunas existentes no desempenho esperado dos servidores. A constatação destas lacunas se dará por meio da avaliação de desempenho por competências, que possibilitará a identificação das possíveis necessidades de desenvolvimento. A gestão de pessoas por competências (GPC) visa basicamente o gerenciamento de lacunas de 
competências existentes na organização, procurando eliminá-las ou minimizá-las. O propósito é aproximar as competências existentes na organização daquelas necessárias para o alcance dos objetivos organizacionais. (CARBONE et al. 2009).

A Figura 3 ilustra o modelo de GPC e a relação entre a estratégia da empresa, sua cultura organizacional, missão, visão e valores. A etapa inicial deste modelo de gestão é a formulação da estratégia da empresa, que implica a definição da sua missão, visão de futuro e de objetivos estratégicos (ARAUJO, 2016).

Figura 3 - Modelo de GPC

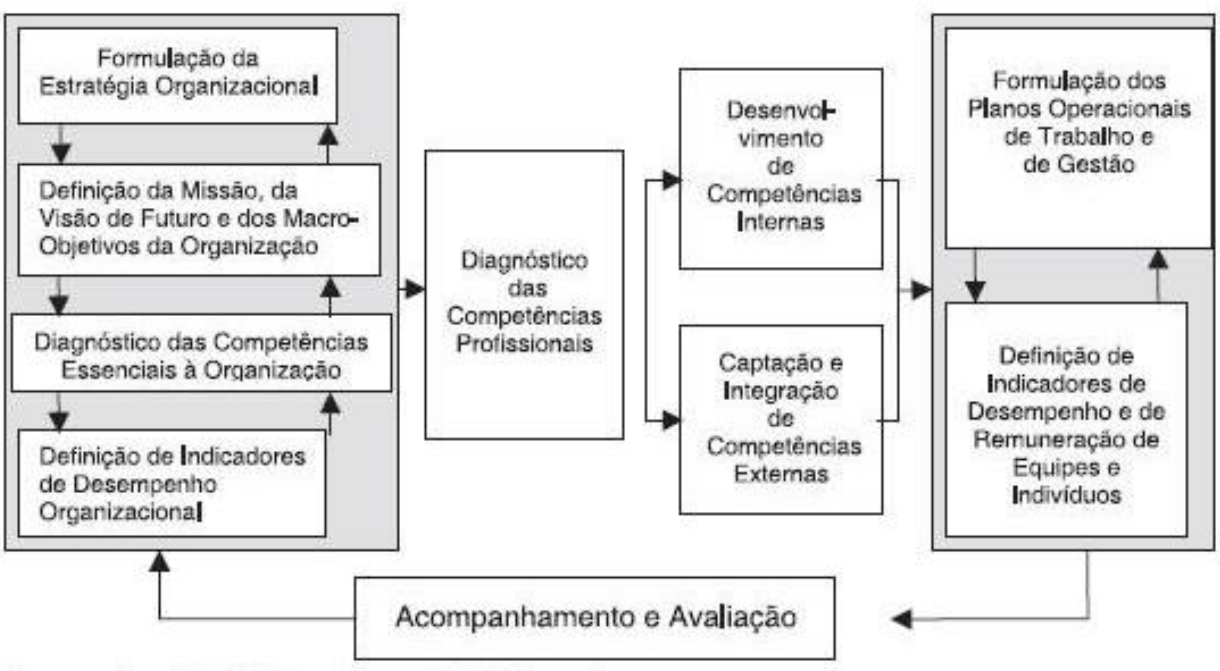

Fonte: Guimarães et al. (2001, apud ARAUJO 2016)

Em seguida, parte-se para a identificação das competências organizacionais necessárias à consecução dos objetivos estabelecidos. São também definidos indicadores de desempenho, medidas da eficiência ou eficácia das ações que devem ser postas em prática a fim de se concretizar a visão de futuro. Na etapa seguinte, realiza-se o diagnóstico das competências necessárias à consecução dos objetivos estratégicos e aquelas existentes na empresa (FERREIRA; ARAUJO, 2015, 2016).

Com base, nesse resultado do diagnóstico, são adotadas decisões de investimento no desenvolvimento e na captação de competências. Essas ações de captação baseiam-se na identificação, obtenção e agregação de habilidades no ambiente externo como recrutamento e seleção de pessoas, por exemplo. Ações de desenvolvimento ou de treinamento visam ao aperfeiçoamento das competências já existentes na organização, por meio de treinamentos e investimento em pesquisa e desenvolvimento (FERREIRA, 2015).

O passo seguinte seria a formulação dos planos operacionais e de gestão, com seus respectivos indicadores de desempenho e de remuneração das equipes e indivíduos. A fim de controlar o processo, é necessário haver um acompanhamento e uma avaliação que possibilite comparar os resultados alcançados com os esperados, para efetuar os ajustes precisos (FERREIRA, 2015).

De acordo com Brandão e Guimarães (2012), esse novo modelo de gestão serve como alternativa aos modelos tradicionais de gerenciamento utilizados pelas organizações. Tendo como pressuposto que a propriedade de competências, 
difíceis de serem desenvolvidas, concede à organização um melhor desempenho em relação ao de seus concorrentes, essa abordagem busca orientar esforços para desenvolver habilidades necessárias à consecução dos objetivos da organização (DURAND, 2000 apud CARBONE et al., 2009).

Nesta mesma concepção, Phahalad e Hamel apud Araujo (2016 p. 55) consideram que a "empresa possui um conjunto de competências essenciais e são estas que diferenciam a empresa de suas concorrentes e lhe asseguram vantagem competitiva de longo prazo". Estas competências essenciais são aquelas que contribuem para a prosperidade da organização, tendo que agregar valor concebido pelo cliente, ser competitivamente única e difícil de ser copiada.

As competências essenciais de acordo com Ferreira (2015) relacionam três critérios principais para definir uma competência essencial. São eles, capacidade de expansão: representam a porta de entrada para potenciais mercados e devem fornecer novas oportunidades de produtos e serviços. A diferenciação entre concorrentes: tem que ser única diferenciada e de difícil imitação em curto prazo. $O$ valor percebido pelo cliente deve ter o valor sendo um diferencial.

\section{GPC NAS ORGANIZAÇÕES PÚBLICAS}

Muitos decretos e resoluções foram publicados para oficializar a implantação da GPC no setor público. Dentre esses decretos, convém citar: o decreto no 5.707/2006 - Governo Federal e a resolução no 111/2010 - Conselho Nacional de Justiça (CNJ).

Estes documentos surgiram devido à necessidade de profissionalizar a atuação dos servidores, de forma alinhada às normas da instituição, com o objetivo de identificar e reconhecer os profissionais que, realizam o seu trabalho com resultados e rapidez (LEME, 2011).

O Decreto no 5.707/2006 trata das políticas e diretrizes para o desenvolvimento de pessoal da administração pública federal direta, autárquica e fundacional. Conceitua a GPC como o "[...] conjunto de conhecimentos, habilidades e atitudes necessárias ao desempenho das funções dos servidores, visando ao alcance dos objetivos da instituição" (BRASIL, 2006, p. 01).

Este mesmo decreto informa que todos os órgãos públicos da Administração Pública Federal devem desenvolver e implementar o modelo de gestão por competência para planejar, executar e avaliar suas ações de capacitação. Destaca, ainda, que tal modelo de gestão deve estar disposto com ações de gestão de pessoas, como planejamento, seleção, capacitação e desempenho (BRASIL, 2006).

Em termos da Administração Pública, Leme (2011) lembra que a implantação de um programa de GPC com um elevado padrão de qualidade e efetividade requer um patrocínio direto da alta direção da organização.

A Resolução no 111, 06/04/2010, estabeleceu o Centro de Formação e Aperfeiçoamento de Servidores do Poder Judiciário - CEAJud, unidade administrativa do Conselho Nacional de Justiça, CNJ, com o propósito de "coordenar e promover, em conjunto com os tribunais, a educação corporativa dos servidores e a qualificação necessária ao alcance dos objetivos estratégicos do Poder Judiciário" (CNJ, 2010, p.02). Em 2010, este conselho também lançou uma Cartilha da Gestão Estratégica do Poder Judiciário e por meio do CEAJud irá 
gerenciar e acompanhar o processo de implementação da GPC em todo o Poder Judiciário, identificando o estágio que cada tribunal se encontra.

Leme (2011) esclarece que há uma necessidade de implantar a gestão por competência no setor público. Na última década, com as diversas ações de reorganização e modernização do setor público nas áreas federais, estaduais e municipais, a GPC está sendo vista como uma importante ferramenta de apoio para estas iniciativas.

\section{DIFICULDADES DE IMPLANTAÇÃO DA GESTÃO POR COMPETÊNCIAS NO SETOR PÚBLICO}

Uma das dificuldades para a adoção deste modelo de gestão no serviço público é a mudança da cultura organizacional. De acordo com Chiavenato (2014), existem culturas conservadoras e rígidas, para que a organização atinja maior eficiência e eficácia é preciso que adote culturas flexíveis e adaptativas. A Gestão de pessoas por Competências representa um desafio para determinada instituição que a desejar implantar, em virtude das mudanças organizacionais que a mesma impõe (AMARAL, 2008).

A área de gestão de pessoas das organizações públicas se esforça para acompanhar os modelos de sucesso de algumas empresas privadas. Porém, a estabilidade dos servidores faz com que eles tendam a não se preocupar com a modernização e buscarem uma gestão que os possibilitem agir com o princípio da eficiência para cumprirem sua missão junto à organização e a sociedade (LEME, 2011).

Assim como, a falta de software na fase inicial do projeto de implantação dificulta a etapa de mapeamento e da aplicação das avaliações de desempenho, no tempo planejado. A ausência de gestores na participação de oficinas de mapeamento de competências também prejudica o andamento (GASPERI, 2013).

Além dessas dificuldades de implantação, Camões (2010 apud SILVA; MELLO, 2013) aponta que as outras dificuldades são a falta de um sistema de informações bem estruturado, a ausência de incentivo à participação em programas de treinamento, além da falta de oportunidade de aplicação prática do conhecimento obtido. Assim, segundo aquele autor, esses problemas se tornam grandes obstáculos ao avanço do modelo de GPC, visto que este modelo exige uma cultura aberta ao conhecimento.

\section{METODOLOGIA}

Esta seção aborda a metodologia empregada neste trabalho. Para tanto serão apresentados a seguir os métodos de pesquisa e os procedimentos técnicos de coleta de dados.

\section{O MÉTODO E AS TÉCNICAS DE COLETAS DE DADOS}

Quanto ao nível, a pesquisa adotou o método descritivo. Segundo Gil (2014) esse tipo de pesquisa tem como objetivo a descrição das características de determinada população ou fenômeno ou o estabelecimento de relações entre variáveis. Cervo e Bervian (2002, p. 66) entendem que pesquisa descritiva é 
"procurar descobrir, com maior exatidão possível, a frequência com que um fenômeno ocorre, sua natureza e características".

Quanto às técnicas de coleta de dados, foram utilizadas pesquisas bibliográficas e de campo. Conforme Marconi e Lakatos (2010, p. 166), a pesquisa bibliográfica "abrange toda bibliografia já tornada pública em relação ao tema de estudo e sua finalidade é colocar o pesquisador em contato direto com tudo o que foi escrito ou dito sobre determinado assunto".

Gil (2014, p.57) afirma que no estudo de campo "estuda-se um único grupo ou comunidade em termos de sua estrutura social, ou seja, ressaltando a interação de seus componentes". Segundo Apolinário (2011), a pesquisa de campo não deve se restringir somente à utilização de documentos, mas também utilizar sujeitos (humanos ou não), para que a pesquisa possua estratégia de campo.

\section{O PÚBLICO-ALVO, O DELINEAMENTO DA PESQUISA E A CONSISTÊNCIA DO QUESTIONÁRIO}

O público-alvo da pesquisa são os colaboradores de um órgão público do Poder Judiciário no Distrito Federal, composto por 2.228 servidores. Para tanto foi realizada uma amostra não aleatória e por conveniência, cujos elementos pesquisados são autos selecionados ou selecionados por estarem disponíveis. Três ambientes do órgão estudado entraram na amostra, onde trabalham 68 servidores dos cargos técnicos ou de analistas, sendo 28 na Coordenadoria de Desenvolvimento de Pessoas, 29 na Coordenadoria de Informações Funcionais e 11 na Divisão de Legislação de Pessoal. No entanto, apenas 50 manifestaram interesse de responder o questionário, sendo $55,7 \%$ responderam-no, ou seja, 40 questionários foram validados.

O questionário utilizado foi do tipo estruturado, com perguntas fechadas de múltipla escolha. Composto por duas etapas, a primeira contemplava 8 itens referentes às informações socioeconômicas do respondente e a segunda, 15 itens relacionados aos fatores que afetam a implantação do modelo de gestão de pessoas por competências. Estes 15 itens utilizara a escala Likert, que consiste em um conjunto de questões apresentados em forma de afirmações, no qual as pessoas escolhem um dos cinco pontos da escala (MARTINS; LINTZ, 2000).

Para testar a compreensão, clareza e vocabulário do questionário, fez-se, em 20 de abril de 2017, um pré-teste com cinco servidores que exerciam os mesmos cargos do público amostral. Segundo Marconi e Lakatos (2010), a importância deste pré-teste está em verificar se o questionário apresenta falhas, questões muito complexas ou perguntas desnecessárias. Além de possibilitar uma estimativa sobre os futuros resultados da pesquisa. De fato, foram necessários proceder algumas correções no questionário quanto a inclusão e exclusão de alguns itens.

A digitação do questionário foi no software Excel, enquanto o processamento dos dados foi por meio pacote estatística SPSS 16.0. Previamente ao processamento da análise fatorial no SPSS, foi calculado o teste de consistência interna do questionário por meio do coeficiente Alfa de Cronbach, obtendo-se um Alfa de 0,72 , cujo valor mínimo considerar um questionário confiável é 0,70 (ALMEIDA; SANTOS; COSTA, 2010, p. 7). 


\section{ANÁLISE DOS RESULTADOS DO ESTUDO DE CASO}

Esta seção tem como objetivo apresentar e analisar os resultados da pesquisa, consoante seu objetivo de identificar a percepção dos colaboradores de um órgão do Poder Judiciário no Distrito Federal sobre os principais fatores e sua natureza que afetam a implantação do modelo de GPC.

Já está em fase de implementação na organização em estudo à GPC, pois esse modelo é considerado necessário e importante para o aprimoramento da gestão de pessoas. Será possível aumentar os investimentos em treinamentos e desenvolvimento de pessoas, de forma a evitar o custo de participação de servidores em cursos que pouco contribuem para a melhoria do desempenho individual e organizacional. Com a implantação desse modelo de gestão de pessoas, a seleção e lotação de servidores também serão aprimoradas, sendo possível identificar em que unidade o servidor apresentará melhores resultados individuais e, portanto, contribuirá ainda mais com os resultados organizacionais.

Quanto ao perfil dos entrevistados, obteve-se que 65\% dos participantes da pesquisa pertencem ao sexo feminino; $39 \%$ estão na faixa etária entre 27 a 37 anos; $20 \%$ têm mais de vinte anos de serviço público; todos detém ensino superior; e 40\% estão na faixa de renda entre 10 e 20 salários mínimos.

Em relação ao conhecimento do modelo de gestão de pessoas por competências, questão 7 do questionário, constatou-se que todos os colaboradores possuem conhecimento acerca do modelo de GPC e do seu objetivo. Na questão seguinte, foi perguntado aos servidores "qual a opinião deles em relação à importância de se implantar um modelo de gestão de pessoas por competências na gestão pública", a resposta, conforme ilustra o Gráfico 1, foi que $70 \%$ consideram a implantação deste modelo na gestão pública muito importante. Esse resultado corrobora a importância de se ter um modelo de GPC na organização em estudo, para efeito de atingimento dos resultados organizacionais.

Gráfico 1 - Importância da implantação de um modelo de Gestão de Pessoas por Competências

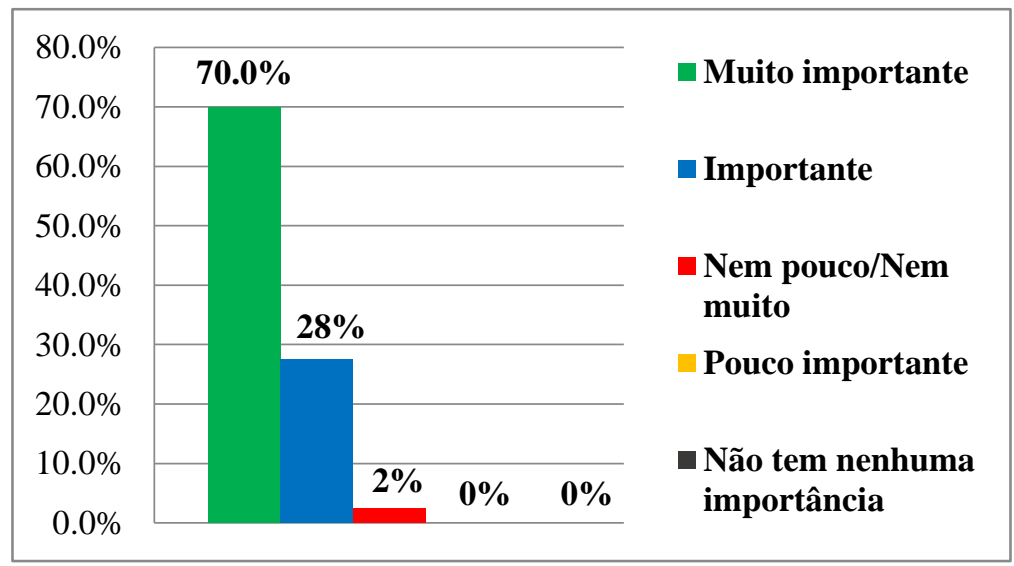

Fonte: Elaborado pelos autores (2017).

A Tabela 1 mostra a frequência de respostas das questões 9 a 16 do questionário. Observa-se que na questão 9, a maioria (80\%) concorda plenamente que existem competências necessárias para o alcance da missão 
organizacional. E isso convalida a afirmação de Carbone et al. (2009), de que os mapeamentos das competências são necessários para o alcance da missão organizacional.

Já em relação ao ambiente de trabalho, tem-se que $75 \%$ concordam plenamente ou concorda que o ambiente de trabalho permite desempenhar com eficácia as suas competências. E isso confirma a afirmação de Rabaglio (2001), quando ressalta que a posse de competências permite ao indivíduo desempenhar, com eficiência suas tarefas em determinada situação.

Quanto à existência de um sistema informatizado para registro, organização e monitoramento de dados coletados sobre o mapa de competências, 30\% nem concordam e nem discordam sobre o papel desse sistema. Mas conforme Camões (2010 apud SILVA; MELLO, 2013), a falta de um sistema de informações bem estruturado é um dos fatores que dificultam implantação do modelo de gestão por competência.

Tabela 1 - Dificuldades do Modelo de gestão por competência no Setor Público - Questões 9 a 16

\begin{tabular}{|c|c|c|c|c|c|}
\hline \multirow[b]{2}{*}{ Questões } & \multicolumn{5}{|c|}{ Frequência relativa das respostas } \\
\hline & 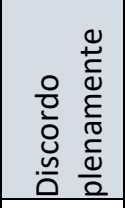 & 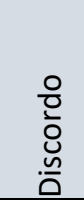 & 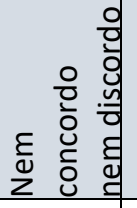 & 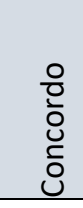 & 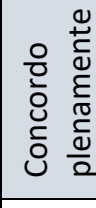 \\
\hline $\begin{array}{l}\text { 9. Você acredita que existem competências } \\
\text { necessárias para o alcance da missão } \\
\text { organizacional. }\end{array}$ & $0 \%$ & $0 \%$ & $0 \%$ & $20 \%$ & $80 \%$ \\
\hline $\begin{array}{l}\text { 10. Seu ambiente de trabalho permite } \\
\text { desempenhar com eficácia as suas } \\
\text { competências. }\end{array}$ & $0 \%$ & $10 \%$ & $15 \%$ & $37 \%$ & $38 \%$ \\
\hline $\begin{array}{l}\text { 11. Na sua seção de trabalho existe um } \\
\text { sistema informatizado para registro, } \\
\text { organização e monitoramento de dados } \\
\text { coletados sobre o mapa de competências. }\end{array}$ & $23 \%$ & $25 \%$ & $30 \%$ & $15 \%$ & $7 \%$ \\
\hline $\begin{array}{l}\begin{array}{l}\text { 12. Na sua concepção, a gestão por } \\
\text { competências resolverá } \\
\text { estruturais da organização. }\end{array} \\
\text { problemas }\end{array}$ & $2 \%$ & $20 \%$ & $38 \%$ & $38 \%$ & $2 \%$ \\
\hline $\begin{array}{l}\text { 13. Na sua visão, a implantação de um } \\
\text { modelo de gestão por competências no } \\
\text { serviço público, permite a instituição um } \\
\text { benefício no alcance dos seus resultados. }\end{array}$ & $0 \%$ & $2 \%$ & $13 \%$ & $37 \%$ & $48 \%$ \\
\hline $\begin{array}{l}\text { 14. Tendo em vista que esse é um novo e } \\
\text { complexo modelo de gestão de pessoas, } \\
\text { foram encontradas dificuldades para definir o } \\
\text { mapa de competências. }\end{array}$ & $0 \%$ & $7 \%$ & $23 \%$ & $55 \%$ & $15 \%$ \\
\hline $\begin{array}{l}\text { 15. No processo de implantação do modelo } \\
\text { de gestão de pessoas por competências, você } \\
\text { visualiza alguma dificuldade na aplicação da } \\
\text { avaliação dos servidores. }\end{array}$ & $2 \%$ & $2 \%$ & $15 \%$ & $53 \%$ & $28 \%$ \\
\hline
\end{tabular}


16. Você concorda que a propriedade de competências, difíceis de serem desenvolvidas, concede à organização um melhor desempenho em relação ao de seus concorrentes.

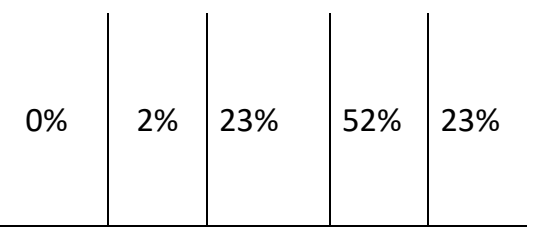

Fonte: Elaborada pelos autores (2017).

Ainda em relação à Tabela 1 , a questão 13 mostra que $85 \%$ dos respondentes concordam plenamente ou concordam que a implantação de um modelo de GPC no serviço público permite a instituição um benefício no alcance dos seus resultados. Leme (2011) esclarece que há uma necessidade de implantar a gestão por competência no setor público. Uma vez que, com as diversas ações de reorganização e modernização do setor público nas áreas federais, estaduais e municipais, a GPC está sendo vista como uma importante ferramenta de apoio para estas iniciativas. Conforme Carbone et al. (2009), a GPC visa aproximar as competências existentes na organização daquelas necessárias para o alcance dos objetivos organizacionais. Chiavenato (2014) afirma ainda que é vantajoso trabalhar com competências porque permite direcionar o foco, concentrar esforços no que é necessário trabalhar para o alcance dos objetivos da empresa.

Observa-se na questão 14 que 55\% dos participantes concordam que, por ser um novo modelo de gestão de pessoas, há dificuldades para definir o mapa de competências. Pois, de acordo com Leme (2011), o mapeamento das competências institucionais é uma etapa de grande importância na execução do projeto, mas, se este for mal elaborado ou tiver baixa assertividade quanto aos desejos de atuação da instituição para com seus servidores, pode ser um fracasso. Carbone et al. (2009), também reforça essa ideia quando frisa que a partir dos mapeamentos das competências necessárias para o alcance da missão organizacional, será possível verificar as lacunas existentes no desempenho esperado dos servidores. Ou seja, é preciso saber quais as competências a organização possuem e quais ela precisa desenvolver em seus colaboradores para alcançar seus objetivos.

Os entrevistados foram questionados se "No processo de implantação do modelo de gestão de pessoas por competências, visualizavam alguma dificuldade na aplicação da avaliação dos servidores", 53\% responderam que concordam com essa afirmação, como mostra a Tabela 1. Isso confirma a afirmação de Gasperi (2013) quando menciona que a falta de software na fase inicial do projeto de implantação dificulta a etapa da aplicação das avaliações de desempenho, no tempo planejado. Pode-se perceber que com a implantação desse novo modelo, a avaliação de desempenho sofre algumas alterações, porque precisa-se de um software específico para avaliar os funcionários, onde os gestores podem não aceitar essa nova forma de trabalho informatizada, resistindo à mudança.

$\mathrm{Na}$ questão 16 foi perguntado aos entrevistados se eles "Concordam que a propriedade de competências, difíceis de serem desenvolvidas, concede à organização um melhor desempenho em relação ao de seus concorrentes". Conforme mostra o Gráfico 2, mais da metade (52\%) dos respondentes concorda com essa afirmação. $O$ que comprova a afirmação feita nesse sentido por Durand (2000, apud CARBONE Et al., 2009), buscando orientar esforços para desenvolver habilidades necessárias à consecução dos objetivos da organização. Phahalad e Hamel (apud ARAUJO, 2016) destacam também que a empresa possui um conjunto de competências essenciais e são estas que diferenciam um 
determinado setor de seus concorrentes e the asseguram vantagem competitiva de longo prazo. Estas competências essenciais são aquelas que contribuem para a prosperidade da organização, devendo agregar valor concebido pelo cliente, ser competitivamente única e difícil de ser copiada.

Gráfico 2 - Propriedade de Competências

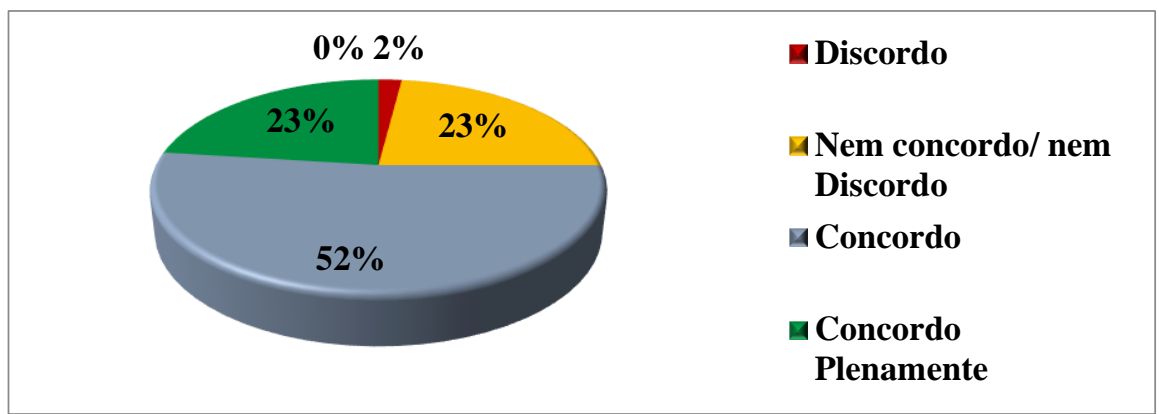

Fonte: Elaborado pelos autores (2017).

A Tabela 4 mostra a frequência de respostas das questões 17 a 23 do questionário. As questões 17, 18 e 20 buscavam saber se a implantação da Gestão de Pessoas por Competências representa um desafio na organização. $\mathrm{Na}$ questão 17 foi perguntado se havia resistência à mudança que impossibilitava a organização em atingir seus objetivos, $48 \%$ concordando com essa afirmação. Reforçando a afirmação de Chiavenato (2014), ao destacar que existem culturas conservadoras e rígidas, no entanto, para que a organização atinja maior eficiência e eficácia é preciso que adote culturas flexíveis e adaptativas.

$\mathrm{Na}$ questão 18, foi questionado se a GPC representa um desafio para qualquer instituição que a deseja implantar. $88 \%$ dos respondentes concordaram totalmente e concordam com essa afirmativa. Amaral (2008) constata que a GPC representa um desafio para determinada instituição que a desejar implantar, em virtude das mudanças organizacionais que a mesma impõe.

No item 20 indagava se a implantação deste programa de Gestão requeria um patrocínio direto da alta direção da instituição, $85 \%$ concordaram totalmente. 0 que reforça o argumento de Leme (2011), de que a implantação de um programa de GPC com um elevado padrão de qualidade e efetividade requer um patrocínio direto da alta direção da organização. Podendo ser verificado na Tabela 2. 
Tabela 2 - Dificuldades do Modelo de Gestão por Competência no Setor Público - Questões 17 a 23

\begin{tabular}{|c|c|c|c|c|c|}
\hline \multirow[b]{2}{*}{ Questões } & \multicolumn{5}{|c|}{ Frequência relativa das respostas } \\
\hline & 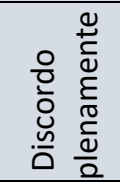 & $\begin{array}{l}0 \\
\frac{0}{0} \\
0 \\
\frac{\mathscr{n}}{0} \\
\end{array}$ & 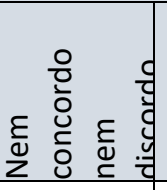 & $\begin{array}{l}\text { 은 } \\
\text { Oั } \\
\text { ¿ } \\
\end{array}$ & 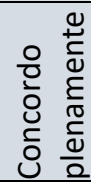 \\
\hline $\begin{array}{l}\text { 17. A resistência à mudança é um } \\
\text { fator que impossibilita a } \\
\text { organização em atingir seus } \\
\text { objetivos com eficiência e eficácia. }\end{array}$ & $2 \%$ & $10 \%$ & $7 \%$ & $48 \%$ & $33 \%$ \\
\hline $\begin{array}{l}\text { 18. A Gestão de Pessoas por } \\
\text { Competências representa um } \\
\text { desafio para qualquer instituição } \\
\text { que a deseja implantar. }\end{array}$ & $0 \%$ & $2 \%$ & $10 \%$ & $53 \%$ & $35 \%$ \\
\hline $\begin{array}{l}\text { 19. A sua capacidade técnica tem } \\
\text { ajudado a conciliar os objetivos de } \\
\text { desempenho organizacionais. }\end{array}$ & $0 \%$ & $0 \%$ & $20 \%$ & $58 \%$ & $22 \%$ \\
\hline $\begin{array}{l}\text { 20. A implantação deste programa } \\
\text { de Gestão requer um patrocínio } \\
\text { direto da alta direção da instituição. }\end{array}$ & $0 \%$ & $0 \%$ & $0 \%$ & $15 \%$ & $85 \%$ \\
\hline $\begin{array}{l}\text { 21. No seu ambiente de trabalho, } \\
\text { existe uma cultura aberta ao } \\
\text { conhecimento (cursos, palestras), } \\
\text { onde seja possível conservar o } \\
\text { aprendizado constantemente. }\end{array}$ & $2 \%$ & $2 \%$ & $5 \%$ & $38 \%$ & $53 \%$ \\
\hline $\begin{array}{l}\text { 22. O desenvolvimento de } \\
\text { conhecimentos, habilidades e } \\
\text { atitudes são condizentes com o seu } \\
\text { posto de trabalho. }\end{array}$ & $0 \%$ & $7 \%$ & $7 \%$ & $48 \%$ & $38 \%$ \\
\hline $\begin{array}{l}\text { 23. Seu cargo atual lhe motiva } \\
\text { executar suas atividades de acordo } \\
\text { com as competências } \\
\text { determinadas. }\end{array}$ & $5 \%$ & $5 \%$ & $15 \%$ & $35 \%$ & $40 \%$ \\
\hline
\end{tabular}

Fonte: Elaborada pelos autores (2017).

As questões 19, 22 e 23 da Tabela 4 queriam saber se os servidores estão motivados, trabalhando no seu cargo ou posto de trabalho atual, a fim de confirmar a necessidade de implantação da GPC no serviço público, selecionando a pessoa certa para a vaga certa. Especificamente, as questões 19 e 23 indagavam se as capacidades técnicas estão ajudando a conciliar os objetivos de desempenho organizacionais, bem como se o cargo atual motiva executar as atividades de acordo com as competências determinadas. Os resultados obtidos foram que 58\% dos entrevistados concordam que suas habilidades técnicas têm ajudado a conciliar os objetivos de desempenho organizacionais. Comprovando o argumento de Zarifian (2008) quando informa que a capacidade técnica expressa que o indivíduo precisa conseguir conciliar os objetivos de desempenho organizacionais em seus atos técnicos quando assumir responsabilidade nas atividades profissionais. Ou seja, compreende os conhecimentos e habilidades que o colaborador precisa ter para desempenhar suas funções (LEME, 2015).

Na questão 22 é perguntado se o entrevistado concorda ou discorda que o desenvolvimento de conhecimentos, habilidades e atitudes são condizentes com 
o seu posto de trabalho. As respostas coletadas foram que $48 \%$ concordam com essa afirmação. Dado que uma parte considerável dos entrevistados está trabalhando de acordo com as competências exigidas para determinada unidade. Segundo França (2013), é necessário fazer a descrição detalhada do cargo, com pré-requisitos e competências fundamentais para determinado cargo ou posto de trabalho antes da seleção do candidato.

Mas em contrapartida o item 23 mostra que 15\% dos respondentes nem concorda e nem discorda que o cargo atual lhe motiva executar suas atividades de acordo com as competências esperadas e 5\% discordam plenamente dessa afirmação. Em conjunto, esses dois percentuais mostram que nem todos os servidores estão satisfeitos nos seus locais de trabalho. $O$ que demonstra a necessidade e importância da implantação do modelo de GPC na organização em estudo. Porém ainda existem dificuldades de implantação desse modelo.

Para encontrar a natureza dos fatores que afetam a implantação do modelo de GPC, segundo os perfis semelhantes de distribuição de resposta, foi realizada uma análise fatorial $\mathrm{R}$ (agrupamento dos diferentes fatores em componentes) do tipo exploratório, empregando o método de rotação varimax.

Na utilização dessa análise, os primeiros testes a serem verificados são o de Kayser-Meyer-Olkin (KMO) e de esfericidade de Bartelett. O teste KMO, neste estudo foi calculado em 0,561, cujo intervalo entre 0,5 e 1 indica a adequabilidade da análise fatorial (PUC-RIO, p.25, enquanto o teste de esfericidade examina a hipótese de que as variáveis não sejam correlacionadas na população, cuja estatística Qui-Quadrada foi altamente significativa $\left(\chi^{2}=242,5\right.$ e valor- $p$ inferior a 0,5 , ou seja, sig $=0,000$ ) em rejeitar essa hipótese, um pressuposto necessário à utilização dessa análise.

A matriz rotacionada dos componentes resultantes bem como os valores das comunalidades (proporção de variância explicadas pelos fatores comuns) estão reproduzidas na Tabela 5. Observa-se nessa tabela que os 15 itens referentes aos fatores que afetam a implantação do GPC foram agrupados em cinco componentes principais.

Tabela 3 - Matriz das Cargas Fatoriais por Componentes Rotacionadas por Varimax

\begin{tabular}{c|c|c|c|c|c|c}
\hline \multirow{2}{*}{ Questões/Naturezas } & \multicolumn{7}{c|}{ Componente } & \multicolumn{2}{c}{\begin{tabular}{c} 
Comunalidades do \\
\cline { 2 - 6 }
\end{tabular}} & $\mathbf{1}$ & $\mathbf{2}$ & $\mathbf{3}$ & $\mathbf{4}$ & $\mathbf{5}$ & itens \\
\hline Item 23 & 893 & $-0,86$ & 190 & $-0,02$ & $-0,11$ & 0,841 \\
\hline Item 22 & 849 & $-0,11$ & 152 & 0,79 & 0,95 & 0,760 \\
\hline Item 10 & 774 & $-0,05$ & $-0,14$ & 141 & 310 & 0,541 \\
\hline Item 21 & 769 & $-0,06$ & -272 & $-0,08$ & -269 & 0,738 \\
\hline Item 9 & 564 & 0,53 & 457 & 0,73 & 0,74 & 0,541 \\
\hline Item 17 & -475 & 464 & 0,24 & 220 & -290 & 0,574 \\
\hline Item 15 & -132 & 812 & 274 & 0,61 & 142 & 0,775 \\
\hline Item 18 & -046 & 777 & 0,35 & -118 & -140 & 0,574 \\
\hline Item 14 & 196 & 741 & 0,00 & 162 & 389 & 0,765 \\
\hline Item 20 & 0,66 & 340 & 727 & $-0,33$ & $-0,02$ & 0,65 \\
\hline Item 19 & 451 & 029 & 719 & $-0,52$ & 0,74 & 0,729 \\
\hline Item 16 & -227 & -038 & 673 & 359 & -103 & 0,645 \\
\hline Item 12 & $-0,25$ & $-0,81$ & $-0,69$ & 883 & 218 & 0,838 \\
\hline Item 13 & 218 & 167 & 233 & 756 & $-0,50$ & 0,703 \\
\hline Item 11 & 075 & 0,89 & $-0,04$ & 120 & 902 & 0,841 \\
\hline
\end{tabular}

Fonte: Elaborada pelos autores (2017). 
A Figura 4 melhora a compreensão deste resultado, ao agrupar os fatores (itens) por componentes, de acordo com o valor da carga fatorial apresentadas na Tabela 1. Quanto maior for este valor maior é a relação do item com o componente. A descrição de cada componente dessa figura é apresentada na sequência.

- A 1a componente se relaciona mais com os itens $09,10,21,22$ e 23 que, de acordo com a Tabela 2, correspondem respectivamente às perguntas: Você acredita que existem competências necessárias para o alcance da missão organizacional; Seu ambiente de trabalho permite desempenhar com eficácia as suas competências; No seu ambiente de trabalho, existe uma cultura aberta ao conhecimento (cursos, palestras), onde seja possível conservar o aprendizado constantemente; $O$ desenvolvimento de conhecimentos, habilidades e atitudes são condizentes com o seu posto de trabalho; Seu cargo atual the motiva executar suas atividades de acordo com as competências determinadas. Por conseguinte, pode-se associar esta $1^{\underline{a}}$ componente com uma variável latente, que reúne os fatores de natureza metodológica de mapeamento, ou seja, as dificuldades metodológicas para implantação do modelo de GPC.

- A 2a componente compreende os itens $14,15,17$ e 18, que correspondem às respectivas perguntas: Tendo em vista que esse é um novo e complexo modelo de gestão de pessoas, foram encontradas dificuldades para definir o mapa de competências; No processo de implantação do modelo de gestão de pessoas por competências, você visualiza alguma dificuldade na aplicação da avaliação dos servidores; A resistência à mudança é um fator que impossibilita a organização em atingir seus objetivos com eficiência e eficácia; A Gestão de Pessoas por Competências representa um desafio para qualquer instituição que a deseja implantar. Inferem-se dessa componente que aqui estão agrupados os fatores de natureza cultural da organização, ou seja, aos problemas culturais da organização que dificultam a implantação do modelo GPC.

Figura 4 - Dificuldades e Naturezas

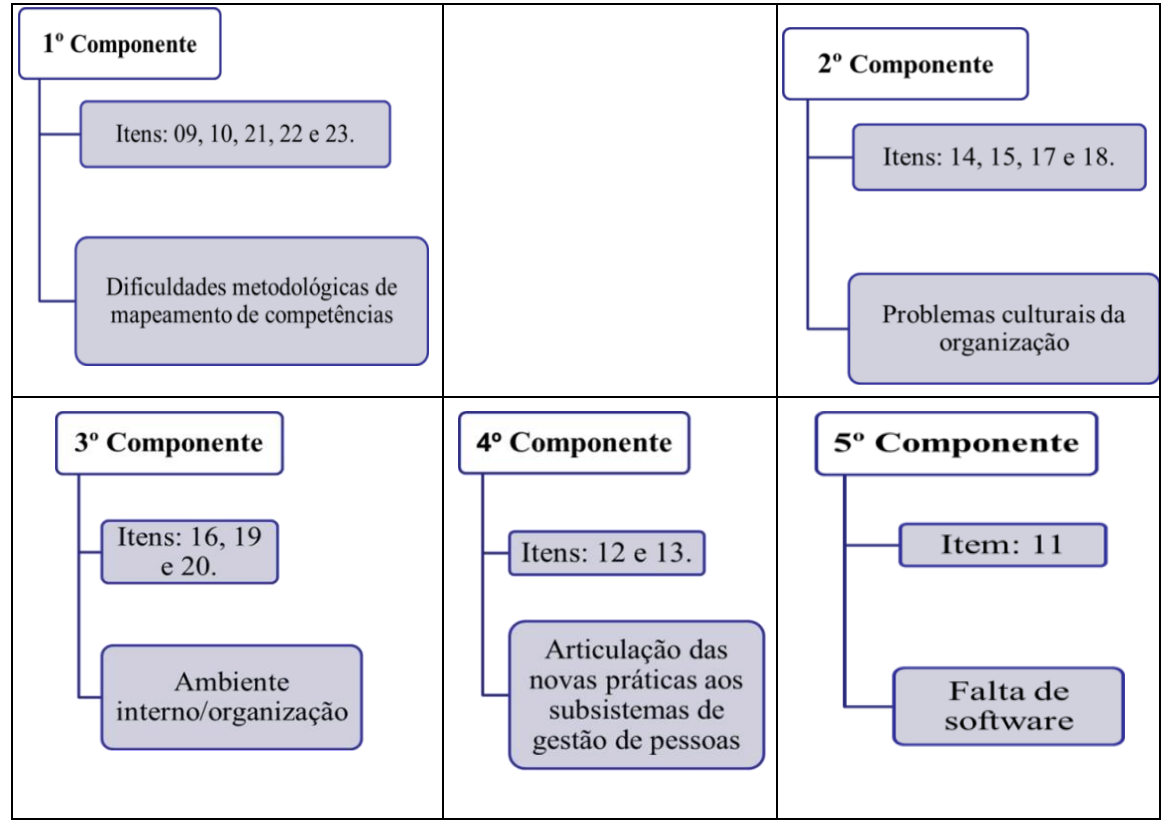

Fonte: Elaborado pelos autores (2017) 
- A 3a componente reúne os itens 16, 19 e 20, que correspondem às respectivas perguntas: Você concorda que a propriedade de competências, difíceis de serem desenvolvidas, concede à organização um melhor desempenho em relação ao de seus concorrentes; A sua capacidade técnica tem ajudado a conciliar os objetivos de desempenho organizacionais; A implantação deste programa de Gestão requer um patrocínio direto da alta direção da instituição. Daqui, depreende-se que este conjunto de fatores se relaciona ao ambiente interno da organização, que podem ser tanto positivos como negativos à implantação do modelo GPC.

- O 4a componente reúne os itens 12 e 13, que correspondem às respectivas perguntas: Na sua concepção, a GPC resolverá os problemas estruturais da organização; Na sua visão, a implantação de um modelo de GPC no serviço público, permite a instituição um benefício no alcance dos seus resultados. Com isso, pode-se deduzir que esta componente está relacionada com articulação das novas práticas aos subsistemas de gestão de pessoas.

- E a 5a componente incorporou apenas o item 11, que corresponde à respectiva pergunta: $\mathrm{Na}$ sua seção de trabalho existe um sistema informatizado para registro, organização e monitoramento de dados coletados sobre o mapa de competências. Logicamente, referindo-se à necessidade do modelo de GPC de contar com software que registre e monitore os dados do mapa de competência.

Por fim, observa-se que essas componentes agrupam fatores de relativa coerência interna, conforme visto pelo coeficiente Alfa de Cronbach. E dada a natureza dessas componentes é possível fazer as seguintes considerações sobre cada uma das variáveis latentes.

- Dificuldades metodológicas de mapeamento de competências, essas dificuldades encontradas estão associadas à falta de preparo da organização quanto ao método para mapear as competências (motivos: existem competências necessárias para o alcance da missão organizacional; o ambiente de trabalho permite desempenhar com eficácia as competências; no ambiente de trabalho, existe uma cultura aberta ao conhecimento, onde seja possível conservar o aprendizado constantemente; o desenvolvimento de conhecimentos, habilidades e atitudes são condizentes com o seu posto de trabalho; o cargo atual lhe motiva executar suas atividades de acordo com as competências determinadas);

- Problemas culturais da organização, uma vez que apresenta um problema em relação à resistência a mudança (motivos: dificuldades para definir o mapa de competências; dificuldade na aplicação da avaliação de desempenho dos servidores. A resistência à mudança é um fator que impossibilita a organização em atingir seus objetivos; A GPC representa um desafio para qualquer instituição que a deseja implantar);

- Ambiente interno/organização, visto que as dificuldades do ambiente interno correspondem aos pontos fortes e fracos da organização (motivos: a propriedade de competências, difíceis de serem desenvolvidas, concede à organização um melhor desempenho em relação ao de seus concorrentes; a capacidade técnica dos servidores ajuda a conciliar os objetivos de desempenho organizacionais; a implantação deste programa de gestão requer um patrocínio direto da alta direção da instituição);

- Articulação das novas práticas aos subsistemas de gestão de pessoas, ou seja, 
representa a falta de combinação das novas práticas dos sistemas de gestão de pessoas, no que diz respeito aos problemas da organização em capacitar seus gestores e funcionários no modelo de GPC (motivos: a GPC resolverá os problemas estruturais da organização; a implantação de um modelo de GPC no serviço público, permite a instituição um benefício no alcance dos resultados).

- Falta de software, pois na instituição em estudo não existe um sistema para registro e organização dos dados coletados sobre o mapa de competências (motivo: na seção de trabalho existe um sistema informatizado para registro, organização e monitoramento de dados coletados sobre o mapa de competências).

\section{CONCLUSÕES E CONSIDERAÇÕES FINAIS}

O trabalho teve como objetivo identificar a percepção dos colaboradores de um órgão do Poder Judiciário no Distrito Federal sobre os principais fatores e sua natureza que afetam a implantação do modelo de gestão de pessoas por competências, GPC.

No desenvolvimento da pesquisa foi utilizado o método de pesquisa descritiva, com apoio dos softwares Excel e o pacote estatístico SPSS. Como técnicas de coleta de dados foram empregadas à pesquisa bibliográfica e estudo de caso.

Diante dos conceitos teóricos e da análise realizada a partir de tabelas, quadros e gráficos, pôde-se identificar alguns fatores que dificultam a implantação desse modelo na gestão pública. A resistência à mudança da cultura organizacional foi uma das dificuldades encontradas, uma vez que obteve um percentual de $48 \%$ na pesquisa realizada. O que gera insegurança por ser um novo modelo de gestão de pessoas, em que os servidores e gestores não tem o pleno domínio.

A dificuldade para definir o mapa de competências e a falta de um sistema informatizado para registro, organização e monitoramento de dados coletados sobre o mapa também atrapalham o processo de implantação do modelo. 55\% das pessoas afirmaram que encontraram obstáculos para definir o mapa de competências, além de que $15 \%$ concordaram que não havia um sistema para organização dos dados coletados. O sistema de informatização contribui para a avaliação de desempenho, registro de dados e controle do processo de implantação do modelo de GPC.

Como os gastos financeiros são altos para a implantação do modelo, pois necessita de licitação para contratação de consultoria especializada na área, sem o apoio da Alta Administração não é possível tal realização, uma vez que pode representar também uma dificuldade de inserção do modelo. Tal hipótese é confirmada quando indaga-se para os entrevistados se a implantação deste programa de gestão requeria um patrocínio direto da alta direção da instituição, o resultado foi que $85 \%$ concordavam totalmente. O que comprova o argumento de Leme (2011), quando enfatiza que a implantação de um programa de GPC com um elevado padrão de qualidade e efetividade requer um patrocínio direto da alta direção da organização.

Além de identificar e discutir a influência dos fatores na implantação do 
modelo de GPC, o estudo também utilizou a análise fatorial exploratória do tipo $\mathrm{R}$ para agrupar os quinzes fatores (itens do questionário) em grupos (componentes), que apresentassem o maior grau de independência possível, segundo o padrão de variação das características desses fatores. Em que pese o tamanho pequeno da amostra, apenas 40 entrevistados, os testes da análise fatorial se mostraram adequados para este tipo de análise, com os 15 fatores que relacionados à implantação do GPC agrupados em cinco componentes, ou seja, nas seguintes variáveis latentes (ou construtos): i) dificuldades metodológicas de mapeamento de competências; ii) problemas culturais da organização; iii) ambiente interno/organização; iv) articulação das novas práticas aos subsistemas de gestão de pessoas; e v) falta de software.

Como considerações finais, fica a sugestão de novos estudos sobre a influência desses fatores na implantação da GPC em instituições privadas. Também são relevantes pesquisas futuras quanto ao alcance dos objetivos organizacionais com utilização do modelo de GPC, considerando-se que várias empresas não atingem seus objetivos estratégicos, devido à falta de profissionais qualificados.

E finalmente, como sugestão à organização em estudo, recomenda-se a elaboração de um plano de desenvolvimento individual com os gestores e servidores, para identificar as lacunas de competências no momento da avaliação de desempenho, e assim melhorar os processos de captação, desenvolvimento e avaliação das competências necessárias ao alcance das metas institucionais. 


\title{
The Competence-based Model: A Case Study in a Federal Public Organ on the Factors Affecting the Implantation of this Mode
}

\begin{abstract}
The study seeks to identify the perception of employees of a federal public agency on the main factors that affect the implementation of the Competence-based management model, CBM, and how to identify the nature of these factors. Regarding the level of the research, the descriptive method was used as data collection procedures, bibliographic research and a case study, with 40 organ servers, selected by non-random sampling and convenience. To find the nature of the factors, according to the characteristic variation pattern, an exploratory factorial analysis of type R was used in order to identify groups of factors with the highest degree of independence possible. Regarding the findings of the research, it is noteworthy, as far as perception is concerned, that all interviewees were aware of the CBM model; All had the necessary skills to achieve the organizational mission; And more than half agreed that because it is a new model of people management, there are many difficulties to define the map of skills, including resistance to change. As to nature, the method grouped the 15 items of the questionnaire into five latent variables, according to the pattern of variation of the characteristics of the items.
\end{abstract}

KEYWORDS: Human Management. Competence-based Management. Factor analysis. Latent Variables. 


\section{REFERÊNCIAS}

ALMEIDA, Diogo; SANTOS, Marco, A.R. dos; COSTA, Antônio F. Branco. Aplicação do Coeficiente Alfa de Cronbach nos resultados de um questionário para avaliação de desempenho da saúde pública. XXXX Encontro Nacional de Engenharia de Produção, São Carlos, 12 a 15 de outtubro de 2010.

AMARAL, Roniberto Morato. Gestão de pessoas por competências em organizações públicas. São Paulo, 2008.

APOLINÁRIO, Fabio. Dicionário de metodologia científica: um guia para a produção do conhecimento científico. 2 ed. São Paulo: Atlas, 2011.

ARAUJO, Antônio de Pádua. Gestão de pessoas por competências e educação corporativa: uma abordagem integrada. Curitiba: CRV, 2016.

BLOOM, B. S. et al. Taxonomia de objetivos educacionais: domínio cognitivo. Porto Alegre: Globo, 1979.

BOYATZIS, Richard E. The competent management: a model for effective performance. New York: John Wiley, 1982.

BRANDÃO, H. P. Mapeamento de competências - métodos, técnicas e aplicações em Gestão de Pessoas. São Paulo: Atlas, 2012.

BRASIL. Decreto federal n⒌707, de 23 de fevereiro de 2006. Institui a Política e as Diretrizes para o Desenvolvimento de Pessoal da administração pública federal direta, autárquica e fundacional, e regulamenta dispositivos da Lei no 8.112, de 11 de dezembro de 1990. Portal do Planalto, Brasília. 2006. Disponível em: $<$ http://www.planalto.gov.br/ccivil 03/ Ato2004-

2006/2006/Decreto/D5707.htm > Acesso em 04 abr. 2017.

CARBone, Pedro Paulo; BRANDÃo, Hugo Pena; LEITE, João Batista Diniz; VILHENA, Rosa Maria de Paula. Gestão por competências e gestão do conhecimento. 3.ed. Rio de Janeiro: Editora FGV, 2009.

CERVO, Amado Luiz; BERVIAN, Pedro Alcino. Metodologia Cientifica. 5.ed. São Paulo: Prentice Hall, 2002.

CHIAVENATO, Idalberto, Gestão de Pessoas: o novo papel dos recursos humanos nas organizações. 4.ed. São Paulo: Manole, 2014. Introdução à teoria geral da administração. 4.ed. São Paulo:

Manole, 2014.

CONSELHO NACIONAL DE JUSTIÇA. Cartilha de gestão estratégica do Poder Judiciário. Brasília, DF: CNJ, 2010. Disponível em: $<$ http://www.tjal.jus.br/apmp/arquivos/a629499b9937114f13a75013e486b54f.p df $>$. Acesso em 04 abr. 2017. 
implementação. Brasília, DF: CNJ, 2016. Disponível em: $<$ http://www.cnj.jus.br/files/conteudo/arquivo/2016/06/680c06d9fb530417e0da 9912aa766872.pdf $>$. Acesso em 04 abr. 2017.

2010. Brasília, DF: CNJ, 2010. Disponível em:
<http://www.cnj.jus.br///images/atos_normativos/resolucao/resolucao_111_06 042010_11102012174743.pdf>. Acesso em 04 abr. 2017.

DUTRA, Joel Souza, Competências: conceitos e instrumentos para a gestão de pessoas na empresa moderna. 1.ed. São Paulo: Atlas, 2007.

FERREIRA, Patricia Itala, Gestão por competência. 1.ed. Rio de Janeiro: LTC, 2015.

FRANÇA, Ana Cristina Limongi, Práticas de Recursos Humanos - PRH: conceitos, ferramentas e procedimentos. 1.ed. São Paulo: Atlas, 2013.

GASPERI, Neuza Terezinha Tissot, Desafios do modelo de gestão de pessoas por competências no setor público. Brasília, 2013.

GIL, Antonio Carlos, Métodos e técnicas de pesquisa social. 6 ed. São Paulo: Atlas, 2014.

LAKATOS, Eva Maria; MARCONI Maria de Andrade. Fundamento de Metodologia Cientifica. 7. ed. São Paulo: Atlas, 2010.

LEME, Rogério, Seleção e entrevista por competências com o inventário comportamental: guia prático do processo seletivo para redução da subjetividade e eficácia na seleção. Rio de Janeiro: Qualitymark, 2007.

- Gestão por competências no setor público. Rio de Janeiro: Qualitymark, 2011

Avaliação de desempenho com foco em competência: a base para remuneração por competências. Rio de Janeiro: Qualitymark, 2015.

MARTINS, Gilberto de Andrade; LINTZ, Alexandre. Guia para elaboração de monografias e trabalhos de conclusão de curso. São Paulo: Atlas, 2000.

PONTIFÍCIA UNIVERSIDADE CATÓLICA DO RIO DE JANEIRO, Análise fatorial. Certificação Digital № 0310444/CA, PUC-Rio, sem data. Disponível em https://www.maxwell.vrac.puc-rio.br/8741/8741 5.PDF, acesso em 10/08/2017.

RABAGLIO, Maria Odete. Seleção por competências. 4 ed. São Paulo: Educator, 2001.

. Maria Odete. Gestão por competência: ferramentas para atração e captação de talentos humanos. Rio de Janeiro: Qualitymark, 2008. 
ROCHA, Eduardo Peixoto, Gestão de pessoas por competências: um enfoque gerencial. 2.ed. São Paulo: Editora Alínea, 2016.

ROESCH, Sylvia Maria Azevedo. Projetos de estágio e de pesquisa em administração: guia para estágios, trabalhos de conclusão, dissertações e estudos de caso. 2. Ed. São Paulo: Atlas, 1999.

SILVA, Francielle Molon da Silva; MELLO, Simone Portella Teixeira. A implantação da : práticas e resistências no setor público. Revista Eletrônica de Administração e Turismo, Rio Grande do Sul, v.2, n. 1, p. 110-127, jan/jun. 2013.

ZARIFIAN, Philippe, Objetivo competência: por uma nova lógica. 1.ed. São Paulo: Atlas, 2008

Recebido: 02 dez. 2017

Aprovado: 12 dez. 2017

DOI: 10.3895/gi.v13n4.7461

Como citar:

LIMA, D. M. S.; MELO, J. A. M. O modelo de gestão de pessoas por competências: um estudo de caso em um órgão público federal sobre os fatores que afetam a implantação deste modelo. R. Gest. Industr., Ponta Grossa, v. 13, n. 4, p. 26-49, out./dez. 2017. Disponível em: <https://periodicos.utfpr.edu.br/rgi>. Acesso em: XXX.

Correspondência:

Dyhele de Macêdo Silva Lima

QNO 18 CJ 81 L 06, número 202, Bairro: Ceilândia Norte, Ceilândia, Distrito Federal, Brasil.

Direito autoral: Este artigo está licenciado sob os termos da Licença Creative Commons-Atribuição 4.0

Internacional. 